\title{
Nursing Duty Hours' Length and the Perceived Outcomes of Care
}

\author{
Mu'taman Jarrar ${ }^{1}$, Hamzah Abdul Rahman ${ }^{2}$, Abdulaziz M. Sebiany ${ }^{1}$, Mahdi S AbuMadini ${ }^{1}$, \\ Hj. Masnawaty $\mathrm{S}^{3}$ \& Christopher Amalraj ${ }^{1}$ \\ ${ }^{1}$ College of Medicine, Imam Abdulrahman Bin Faisal University, Dammam, Saudi Arabia \\ ${ }^{2}$ College of Business, Universiti Utara Malaysia, Kedah, Malaysia \\ ${ }^{3}$ Faculty of Economics, Universitas Negeri Makassar Indonesia, Indonesia \\ Correspondence: Mu'taman Jarrar, RN, PhD Healthcare Quality Management, Vice Deanship for Quality and \\ Development, College of Medicine, Imam Abdulrahman Bin Faisal University, King Fahd Hospital of the \\ University, P.O. Box 1982, Dammam 31441, Saudi Arabia. Tel: 96-654-471-8523. E-mail: \\ mutaman.jarrar@yahoo.com
}

Received: January 16, 2018 Accepted: February 1, 2018 Online Published: February 26, 2018

doi:10.5539/gjhs.v10n4p1 URL: https://doi.org/10.5539/gjhs.v10n4p1

\begin{abstract}
Background and objective: Working long shifts are associated with fatigue, medical errors and poor outcomes of care. However, there is a lack of guide that can provide policy-makers the optimal duty length in the Malaysian hospitals. The study aims to investigate the impact of nursing duty hours' length on the quality and safety of care delivered in the "Medical-Surgical Wards" in Malaysia.
\end{abstract}

Method: Cross-sectional study was carried out on 12 private hospitals. Data was collected, through questionnaires, from 652 nurses (61.8\% response rate). Stratified random sampling was used in the study. Regression analyses were conducted to explore the impact of the nursing duty hours' length on the care quality and safety.

Findings: The length of nurses' duty hours is not significantly affecting care quality $(\mathrm{F}=1.27$ and $\mathrm{P}$ value $=0.28)$ and patient safety $(\mathrm{F}=1.81$ and $\mathrm{P}$ value $=0.13)$, at $\mathrm{p}<0.05$ significance level.

Conclusion: Nurse working in hospitals with 10 -hours night shift had perceived poor quality $(\mathrm{B}=-0.11, \mathrm{t}=-1.64$, $\mathrm{p}=0.10)$; and unsafe care $(\mathrm{B}=-0.17, \mathrm{t}=-2.40, \mathrm{p}=0.02)$. Policy makers in Malaysian hospitals can benefit from the study by restructuring duty hours' length in their hospital.

Keywords: duty hours' length, quality, safety, medical ward, surgical ward

\section{Introduction}

Quality and safety are priority for leaders in healthcare sectors at the globe. In the last 17 years since the report "To Err is Human" there are disciplinary efforts and interventions to reform systems for optimizing health and healthcare (IOM, 2000). However, preventable deaths and adverse events are substantial (Leape, 2015). In USA, a total of 4 hundred thousand adverse events led to 2.1 hundred thousand deaths annually (James, 2013). Shortage of nursing led to increase the pressure in healthcare service (Cramer, Jones, \& Hertzog, 2011; Hinno, Partanen, \& Vehviläinen-Julkunen, 2011; Mu'taman Jarrar, Abdul Rahman, \& Shamsudin, 2015; Knight, 2015; McHugh et al., 2016; Watson et al., 2016; Wolfe, 2011). Nurses working longer shifts (Stimpfel \& Aiken, 2013), and had workload led to burnout jeopardizing the processes of caring (Van Bogaert, Clarke, Willems, \& Mondelaers, 2013). In Malaysia, hospitals are overcrowded (MOH, 2011). Several system reforms have been conducted (MOH, 2011). However, adverse events and legal claims are increasing and nurses working longer shift (Mu'taman Jarrar \& Abdul Rahman, 2015). Therefore, the study aims to explore the effect of duty hours' length on the quality and safety of caring patients in the Malaysian hospitals.

\section{Literature Review}

Duty hours' length is significantly associated with the nurses' perceived quality and safety of patients' care (Stimpfel \& Aiken, 2013). There is a lack of guide that can provide policy-makers the optimal duty length (Stone et al., 2006). Many studies have illustrated that nurse duty hours' length has a mixed effect on patient safety and quality outcomes (Estabrooks et al., 2009; Philibert, Nasca, Brigham, \& Shapiro, 2013; Stone et al., 2006). For instance, some studies have found that limiting duty hours leads to decreased continuity of care and increased workload, which in turn negatively affect patient safety and staff performance (Philibert et al., 2013). Others have found that nurses assigned for 12-hour shifts had higher job satisfaction and are less fatigued than nurses assigned 
for 8-hour shifts (Stone et al., 2006). On the other hand, limiting working hours reduces burnout and fatigue, and enhances staff mood and sleeping hours, which in turn lead to improved performance (Philibert et al., 2013). Similarly, Estabrooks et al. (2009) found contradictory results regarding shift length and the quality of patient care. Bhavsar et al. (2007) found that duty hours limit improve the process quality, but does not significantly affect the clinical quality outcome (mortality rate and adverse events). So, length of nurses' duty hours has a mixed effect on the quality and safety. These inconsistent findings show the importance to explore the effect of nurse duty hours' length on the quality and safety of patient care for better understanding of these relationships.

Restructuring working hours can improve care outcomes and decrease length of stay for patients with coronary heart disease (Bhavsar et al., 2007). Gajic et al. (2008) illustrated that by implementing a new duty program, satisfaction of patients, families and staff increased, the quality of care improved and the length of stay decreased. On the other hand, longer shifts are associated with fatigue, medical errors and greater risk of staff over-abusing alcohol and cigarettes (Estabrooks et al., 2009). In Malaysia, a study in seven Malaysian hospitals has found that increasing demands of care and long duty hours, with shortage in resources led to jeopardize the sustainable care outcomes (Drake, 2013). These findings illustrate the importance of investigating the effect of nurse duty hours' length on the quality and safety of patient care in Malaysia (Estabrooks et al., 2009).

According to Stone et al. (2006), there are two types of work shifts: 8-hour shifts (A shift, B shift and C shift); or 12-hour shifts (day shift and night shift). Surgical procedures performed at night lead to increasing the length of stay and readmission, although it is not significantly related to mortality and morbidity rate. Turrentine et al. (2010) stated that non-emergent surgical procedures conducted at night solves overcrowding during the day at peak times. In Malaysia, there are two types of working shifts: 7-hours morning, 7-hours afternoon and 10-hours night shifts; or 12-hour shifts (day shift and night shift). These shifts pattern raise the concern of examine the association of shift lengths on the outcomes of care in Malaysia.

\section{Method}

\subsection{Design and Data Collection}

Cross-sectional research was conducted in twelve hospitals in Malaysia. Stratified random sampling was performed based on the hospital size. Hospitals clustered to small, medium and large size based on number of beds $>100,100-199$ and $<200$, respectively. Ethical approvals obtained from the hospital participated in the study. Self-administered questionnaire has been distributed for nurses working in the all shifts. Nurses asked to choose among four categories of the shift length: 7-hours, 8-hours, 10- hours and 12-hours. Nurses asked to rate quality and safety in a five point scale. Nurses rated the quality in their ward last working shift and in the last year, for measuring care quality. Further, nurses rated the frequency of adverse events (Groene et al., 2010); and the overall patient safety in their wards (Aiken et al., 2012). A total of 652 of nurses agreed to participate and replied back a completed survey forms with response rate $61.8 \%$.

\subsection{Data Analysis}

Multivariate regression analyses using SPSS 21 were performed to examine the effect of nurse duty hours' length on the quality and safety of care provided on the hospitals in Malaysia. The mean value calculated for each scale: the scale of measuring Quality (the quality in last shift and last year); and the scale for measuring Patient safety (the agreement of the frequency of the adverse events and the overall patient safety in the ward). Shift length categories were coded as Dummy variables. 7-hourse shift was considered as reference group of these variables. Reference group chosen as expected to score higher perceived quality and safer care (Cohen, Cohen, West, \& Aiken, 2003; Hardy, 1993; West, Aiken, \& Krull, 1996). 0.05 was considered as the significant level of P value.

Multivariate assumptions were tested. Factor analysis for validity and Cronbach's alpha for instruments reliability were performed, and reveals that the instruments used in the study were valid and reliable with Cronbach's alpha more than 0.70 (Pallant, 2011; Sekaran \& Bougie, 2010).

\section{Findings}

\subsection{Respondents' Characteristics}

The respondents in the study were $99.0 \%$ Malaysian with three main races: $60.0 \%$ were Malay; $21.6 \%$ Chinese and $14.2 \%$ Indians. The respondents were mostly less than 30 years old $(77.3 \%)$, and $78.4 \%$ had experience more than one year in the medical or surgical ward. $47.7 \%$ hours of the nurses are working 7 -hour shifts; while $17.5 \%$ are working 8 -hour shifts; $16.8 \%$ are working 10 -hour shifts; $16.0 \%$ are working 12 -hour shifts; and $2.1 \%$ others (including nurses working more than one-shift or "double shifts"). The most prominent shift type is the morning shift (38.1\%); while $15.1 \%$ are working in the afternoon shift; $19.9 \%$ are working in the evening shift; and $26.9 \%$ others (including those nurses working 12-hour "day and night shift" or "double shifts"). 


\subsection{Length of Nurses' Duty Hours and Quality of Care}

Multivariate regression analyses of the impact of nursing duty hours' length on the quality and safety of patient care in Malaysian hospitals are shown in Tables 1 and 2; respectively.

Length of nurses' duty hours dimension includes four dummy variables. Table 1 provides the results of analysis in order to test the hypotheses:

H1: Length of nurses'duty hours has a significant effect on the care quality.

$\mathrm{H} 1_{0}$ : Length of nurses' duty hours has no significant effect on the care quality.

Table 1. Multiple regression analysis results of length of nurses' duty hours on the care quality

\begin{tabular}{llllll}
\hline Duty hours & B & SE & $\boldsymbol{\beta}$ & t & P \\
\hline Constant & 3.74 & 0.03 & & 110.38 & 0.00 \\
8-hour shifts & 0.07 & 0.07 & 0.05 & -1.04 & 0.30 \\
10-hour shifts & -0.11 & 0.07 & -0.07 & -0.16 & 0.88 \\
12-hour shifts & -0.01 & 0.07 & -0.01 & 0.15 & 0.88 \\
Other shifts & 0.03 & 0.17 & 0.01 & & \\
\hline $\mathrm{R}^{2}$ & 0.01 & & & \\
F & 1.27 & & & \\
Significance of F & 0.28 & & & & \\
\hline
\end{tabular}

Significance level: *: $\mathrm{p}<0.05$.

The summarized results in Table 1 show that $\mathrm{F}=1.27$ and $\mathrm{P}=0.28$, indicating that the effect of length of nurses' duty hours on the quality is not significant. $\mathrm{R}^{2}$ indicates that the length of nurses' duty hours variable predicts 0.01 of variances in the quality. However, the Beta Coefficient indicates that nurses working 10-hours $(\mathrm{B}=-0.11, \mathrm{t}=-1.64$, $\mathrm{p}=0.10)$ and 12 -hour shifts $(\mathrm{B}=-0.01, \mathrm{t}=-0.16, \mathrm{p}=0.88)$ are negatively associated with the care quality compared to nurses working 7-hour shifts. However, these negative associations are not significant at $\mathrm{p}<0.05$ level of significance for predicting the care quality.

\subsection{Length of Nurses' Duty Hours and Safety of Patient Care}

Table 2 shows the analysis results of the effect of nurses' duty hours' length on patient safety in order to test the hypotheses:

H2: Length of nurses' duty hours has a significant effect on the safety of patient care.

$\mathrm{H} 2_{0}$ : Length of nurses' duty hours has no significant effect on the safety of patient care.

Table 2. Multiple regression analysis results of length of nurses' duty hours on patient safety

\begin{tabular}{llllll}
\hline Duty hours & $\mathbf{B}$ & $\mathbf{S E}$ & $\boldsymbol{\beta}$ & $\mathbf{t}$ & $\mathbf{P}$ \\
\hline Constant & 3.64 & 0.04 & & 103.43 & 0.00 \\
8-hour shifts & -0.03 & 0.07 & -0.02 & -0.40 & 0.69 \\
10-hour shifts & $-0.17^{*}$ & 0.07 & -0.11 & -2.40 & 0.02 \\
12-hour shifts & -0.11 & 0.07 & -0.07 & -1.56 & 0.12 \\
Other shifts & -0.15 & 0.17 & -0.04 & -0.84 & 0.40 \\
\hline $\mathrm{R}^{2}$ & 0.01 & & & & \\
$\mathrm{~F}$ & 1.81 & & & & \\
Significance of F & 0.13 & & & &
\end{tabular}

Significance level: *: $\mathrm{p}<0.05$.

The summarized results in Table 2 show that $\mathrm{F}=1.81$ and $\mathrm{P}=0.13$, indicating that the effect of length of nurses' duty hours on patient safety is not significant. The $\mathrm{R}^{2}$ value indicates that length of nurses' duty hours variable 
predicts 0.01 of variances in patient safety. However, the Beta Coefficient indicates that increasing the length of nurses' duty hours leads to decreased patient safety compared to nurses working 7-hour shifts. However, these negative associations are not significantly predicting the perceived patient safety among nurses working 8 and 12 hours shifts. While nurses working 10 -hour shifts $(\mathrm{B}=-0.17, \mathrm{t}=-2.40, \mathrm{p}=0.02)$ have perceiving that this shift type negatively impact on patient safety compared to nurses working 7-hour shifts at a $p<0.05$ level of significance. These findings raise the concern to explore the causes led to poor quality $(B=-0.11)$ and safety $(B=-0.17)$ in this particular shift (10-hour shifts) compared with other shifts in Malaysia.

\section{Discussion}

Regression analyses results of the effect of length of nurses' duty hours, as shown in Tables 1 and 2, revealed an insignificant effect on both the quality and safety at $\mathrm{p}<0.05$ level of significance. These are consistent with previous studies. Scholars have found that staff duty hour has a mixed effect on quality and safety of patient care (Estabrooks et al., 2009; Philibert et al., 2013; Stone et al., 2006). Some have found that working 8-hour shifts is negatively associated with the outcomes of care (Stone et al., 2006). Stone et al. (2006) found that nurses working for 12-hour shifts have higher job satisfaction and are less fatigued than those working for 8-hour shifts, while others found that working 8-hour shifts is positively associated with outcomes of care and reducing burnout and fatigue (Bhavsar et al., 2007). For instance, working 8-hour shifts reduces burnout and fatigue and enhances staff's mood and sleeping hours, which in turn lead to improved performance (Philibert et al., 2013). In addition, Bhavsar et al. (2007) found that duty hours limit improves the process quality, but does not significantly affect the clinical outcome of quality. These results show that the length of nurses' duty hours might indirectly affects the outcomes through the process factor, and there is at least one intervening factor with a positive sign that makes the relationship insignificant and inconsistent among previous studies in a different context. Study conducted in Malaysia shows that patient-centered care is significantly mitigate the shortage of nurses (Mu'taman Jarrar, Rahman, Minai, AbuMadini, \& Larbi, 2018). Nurses working longer shift might spend more time with the patients to explain the procedures or the sequences of the treatment. This could lead to enhance the outcomes of care (quality and safety) and explains these inconsistent associations. Thus, further study required to examine these relationships considering the shift length as independent variable to examine the mixed effect of the effect of shift length on the outcomes of care. Nurses working longer shift might have more time to spend with the patient or his/her family to explain further about his/her health status, treatment procedure, right and responsibilities.

The unstandardized coefficient of the nurses working 10-hour shifts $(\mathrm{B}=-0.11)$; and working 12-hour shifts $(B=-0.01)$ negatively affects the quality compared to nurses working 7-hour shifts. This negative impact is not significant at $\mathrm{p}<0.05$ significance level of predicting the quality. On the other hand, nurses working 10-hour shifts $(B=-0.17)$ has a significant negative impact on patient safety compared to nurses working 7-hour shifts at $\mathrm{p}<0.05$ significance level of nurses working in the medical or surgical wards in Malaysian hospitals. So, Managers need to critically evaluate their duty hours' system for nurses working in hospitals with 7-hours morning; 7-hours afternoon; and 10-hours night shifts. Nurses working at night shift in these hospitals with 10-hour shifts perceived poor quality and unsafe care provided at their shift. Leadership support, nurse-physician relationships, workload and other environmental factors need to be explored for better understanding of these relationships.

Managers and policy makers can benefit from this study by restructuring duty hours' length especially for hospitals having the pattern 7-7-10 shifts length. This study used self administered questionnaire. Further research required by doing longitudinal, observational or experimental data to generalize the findings of the study. The study required to be replicated in other context with further environmental factors for better understanding of predictors jeopardizing healthcare systems everywhere.

\section{Conclusion}

This study explored the impact of nursing duty hours' length on the perceived quality and safety in Malaysian hospitals. There is mixed effect of the associations between duty hours' length and the outcomes of care. However, Nurses working 10-hours night shift had lower perceived outcomes of care than other shifts. Policymakers required considering these findings by restructuring the working hours or providing incentives, training or increase their engagement for those nurses at this particular night shift. However, 12-hours day or night shift was not affecting the outcomes of care. These mixed associations' raise the concern for further research by including further environmental variables and examine process factor with positive sign suppresses these negative associations. These will help to strengthen healthcare systems.

\section{Competing Interests Statement}

The authors declare that there are no competing or potential conflicts of interest. 


\section{References}

Aiken, L. H., Sermeus, W., Van den Heede, K., Sloane, D. M., Busse, R., Mckee, M., ... Smith, H. L. (2012). Patient safety, satisfaction, and quality of hospital care: cross sectional surveys of nurses and patients in 12 countries in Europe and the United States. British Medical Journal, 344(e1717), 1-14. https://doi.org/10.1136/bmj.e1717

Bhavsar, J., Montgomery, D., Li, J., Kline-Rogers, E., Saab, F., Motivala, A., ... Eagle, K. A. (2007). Impact of duty hours restrictions on quality of care and clinical outcomes. The American Journal of Medicine, 120(11), 968-974. https://doi.org/10.1016/j.amjmed.2007.07.026

Cohen, J., Cohen, P., West, S., \& Aiken, L. (2003). Applied multiple regression/correlation analysis for the behavioral sciences. Lawrence Erlbaum Associates. Retrieved from http://books.google.com/books?hl=en\&lr=\&id=gkalyqTMXNEC\&oi=fnd\&pg=PP1\&dq=Applied+multiple + regression/+correlation+analysis + for + the + behavioral + sciences\&ots $=t Q C V 02 m b c h \& s i g=k b t L M N F z q J W$ myNgVxNV-Owh07s

Cramer, M. E., Jones, K. J., \& Hertzog, M. (2011). Nurse staffing in critical access hospitals: structural factors linked to quality care. Journal of Nursing Care Quality, 26(4), 335-343. https://doi.org/10.1097/NCQ.0b013e318210d30a

Drake, R. (2013). Nursing workforce planning: insights from seven Malaysian hospitals. British Journal of Nursing, 22(2), 95-100.

Estabrooks, C. A., Cummings, G. G., Olivo, S. a, Squires, J. E., Giblin, C., \& Simpson, N. (2009). Effects of shift length on quality of patient care and health provider outcomes: systematic review. Quality \& Safety in Health Care, 18(3), 181-188. https://doi.org/10.1136/qshc.2007.024232

Gajic, O., Afessa, B., Hanson, A. C., Krpata, T., Yilmaz, M., Mohamed, S. F., .. Wylam, M. E. (2008). Effect of 24-hour mandatory versus on-demand critical care specialist presence on quality of care and family and provider satisfaction in the intensive care unit of a teaching hospital. Critical Care Medicine, 36(1), 36-44. https://doi.org/10.1097/01.CCM.0000297887.84347.85

Groene, O., Klazinga, N., Wagner, C., Arah, O. A., Thompson, A., Bruneau, C., \& Suñol, R. (2010). Investigating organizational quality improvement systems, patient empowerment, organizational culture, professional involvement and the quality of care in European hospitals: the "Deepening our Understanding of Quality Improvement in Europe (DUQuE)" proje. BMC Health Services Research, 10(1), 281. https://doi.org/10.1186/1472-6963-10-281

Hardy, M. (1993). Regression with dummy variables (1st ed). SAGE Publications Ltd. Retrieved from $\mathrm{http} / /$ books.google.com/books?hl=en\&lr=\&id=EzLffJlYISEC\&oi=fnd\&pg=PR5\&dq=Regression+with+D ummy+variable\&ots $=$ R81XjXqfSx\&sig=lnNBq6o1 hwewjSygDJeQDJSyJTw

Hinno, S., Partanen, P., \& Vehviläinen-Julkunen, K. (2011). Hospital nurses' work environment, quality of care provided and career plans. International Nursing Review, 58(2), $255-262$. https://doi.org/10.1111/j.1466-7657.2010.00851.x

IOM. (2000). To Err Is Human: Bulding a Safer Health System. National Academy Press, Washington DC.

James, J. T. (2013). A new, evidence-based estimate of patient harms associated with hospital care. Journal of Patient Safety, 9(3), 122-128. https://doi.org/10.1097/PTS.0b013e3182948a69

Jarrar, M., \& Abdul Rahman, H. (2015). Optimizing Quality of Care and Patient Safety in Malaysia: The Current Global Initiatives, Gaps and Suggested Solutions. Global Journal of Health Science, 8(6), 75-85. https://doi.org/10.5539/gjhs.v8n6p75

Jarrar, M., Abdul Rahman, H., \& Shamsudin, A. S. (2015). The Impact of Patient to Nurse Ratio on Quality of Care and Patient Safety in the Medical and Surgical Wards in Malaysian Private Hospitals: A Cross-sectional Study. Asian Social Science, 11(9), 326-332. https://doi.org/10.5539/ass.v11n9p326

Jarrar, M., Rahman, H. A., Minai, M. S., AbuMadini, M. S., \& Larbi, M. (2018). The function of patient-centered care in mitigating the effect of nursing shortage on the outcomes of care. The International Journal of Health Planning and Management, (August 2017), 1-10. https://doi.org/10.1002/hpm.2491

Knight, L. D. (2015). Staffing Ratios and Patient Outcomes: Looking Beyond Nurses, Doctors, and Survival at ICU Discharge. Critical Care Medicine, 43(6), e208-e209. https://doi.org/10.1097/CCM.0000000000000995

Leape, L. (2015). Hospital Readmissions Following Surgery Turning Complications Into “ Treasures.” Journal of the American Medical Association, 313(5), 467-468. https://doi.org/10.1001/jama.2014.18614.3 
McHugh, M. D., Rochman, M. F., Sloane, D. M., Berg, R. a, Mancini, M. E., Nadkarni, V. M., ... Aiken, L. H. (2016). Better Nurse Staffing and Nurse Work Environments Associated With Increased Survival of $\begin{array}{lllll}\text { In-Hospital Cardiac Arrest Patients. Medical } & \text { Care, }\end{array}$ https://doi.org/10.1097/MLR.0000000000000456

MOH. (2011). Country health plan 10 th Malaysia plan 2011-2015. Retrieved from http://www.moh.gov.my/images/gallery/Report/Country_health.pdf

Pallant, J. (2011). SPSS Survival Manual (4th ed). British library. Retrieved from http://scholar.google.com/scholar?hl=en\&btnG=Search\&q=intitle:SPSS+Survival+Manual\#7

Philibert, I., Nasca, T., Brigham, T., \& Shapiro, J. (2013). Duty-hour limits and patient care and resident outcomes: can high-quality studies offer insight into complex relationships? Annual Review of Medicine, 64, 467-4683. https://doi.org/10.1146/annurev-med-120711-135717

Sekaran, U., \& Bougie, R. (2010). research Methodology for Business (5th ed). John Wiley \& Sons Ltd.

Stimpfel, A., \& Aiken, L. (2013). Hospital staff nurses' shift length associated with safety and quality of care. Journal of Nursing Care Quality, 28(2), 122-129. https://doi.org/10.1097/NCQ.0b013e3182725f09.Hospital

Stone, P. W., Du, Y., Cowell, R., Amsterdam, N., Helfrich, T. A., Linn, R. W., ... Mojica, L. A. (2006). Comparison of nurse, system and quality patient care outcomes in 8-hour and 12-hour shifts. Medical Care, 44(12), 1099-1106. https://doi.org/10.1097/01.mlr.0000237180.72275.82

Turrentine, F. E., Wang, H., Young, J. S., \& Calland, J. F. (2010). What is the safety of nonemergent operative procedures performed at night? A study of 10,426 operations at an academic tertiary care hospital using the American College of Surgeons national surgical quality program improvement database. The Journal of Trauma, 69(2), 313-319. https://doi.org/10.1097/TA.0b013e3181e49291

Van Bogaert, P., Clarke, S., Willems, R., \& Mondelaers, M. (2013). Nurse practice environment, workload, burnout, job outcomes, and quality of care in psychiatric hospitals: a structural equation model approach. Journal of Advanced Nursing, 69(7), 1515-24. https://doi.org/10.1111/jan.12010

Watson, S. I., Arulampalam, W., Petrou, S., Marlow, N., Morgan, a S., \& Draper, E. S. (2016). The effects of a one-to-one nurse-to-patient ratio on the mortality rate in neonatal intensive care: a retrospective, longitudinal, population-based study. Archives of Disease in Childhood - Fetal and Neonatal Edition, 101(3), F195-F200. https://doi.org/10.1136/archdischild-2015-309435

West, S. G., Aiken, L. S., \& Krull, J. L. (1996). Experimental personality designs: Analyzing categorical by continuous variable interactions. Journal of Personality, 64(1), 1-48.

Wolfe, W. A. (2011). Adequacy of dialysis clinic staffing and quality of care: a review of evidence and areas of needed research. American Journal of Kidney Diseases: The Official Journal of the National Kidney Foundation, 58(2), 166-176. https://doi.org/10.1053/j.ajkd.2011.03.027

\section{Copyrights}

Copyright for this article is retained by the author(s), with first publication rights granted to the journal.

This is an open-access article distributed under the terms and conditions of the Creative Commons Attribution license (http://creativecommons.org/licenses/by/4.0/). 